\title{
Design Options for Supply Chain Visibility Services - Learnings from Three EPCIS Implementations
}

\author{
Ralph Tröger, GS1 Germany, troeger@gs1-germany.de \\ Rainer Alt, Leipzig University, rainer.alt@uni-leipzig.de
}

Published in: Electronic Markets 27(2017)2, pp. 141-156. DOI: 10.1007/s12525-016-0231-4

\begin{abstract}
Supply chains in many industries are experiencing an ever-growing complexity. They involve many actors and, similar to intra-organizational processes, visibility is an important enabler for managing supply chains in an inter-organizational setting. It is the backbone of advanced supply chain (event) management solutions, which serve to detect critical incidents in time and to determine alternative actions. Due to the numerous parties involved, distributed supply chains call for a modular system architecture that aims at re-using visibility data from standardized sources. Following the wide variety of supply chain configurations in many industries there are also many options to design such services. This paper sheds light on these aspects by conducting a case study on EPCIS, a global service specification for capturing and sharing visibility data. Based on three implementations, it shows the main design options for a supply chain visibility service, generic operator models as well as major potentials.
\end{abstract}

Keywords: Supply Chain Management, EPCIS, Visibility, Service-orientation, Supply Chain Event Management, Service-oriented Architecture (SOA) 


\section{Introduction and motivation}

The world of logistics depends on the capability of making information available to all parties participating in a supply chain (SC) or a supply network. This observation has become widely known with research on the bullwhip-effect (Lee et al. 1987), which revealed that inefficiencies in sharing information are also associated with inefficiencies in the physical flow of goods. Although many businesses have entered the digital age by implementing internal information systems (IS) and are capable of communicating via the internet, SC information is still often not shared, shared incompletely or re-entered manually. For example, a study among 220 automotive companies found that in the mid-2000s an astonishing 79\% of all information on shipments was still “entered redundantly into the various stakeholder IT systems” (Denno 2013, p. 617). Obviously, this situation is inadequate for agile SC concepts (Christopher 2000) and might explain why available solutions (e.g. from express carriers, such as Fedex) are realized as closed systems.

The consequences are severe since businesses in the logistics sector operate on thin margins. First of all, improved information on available cargo could increase capacity utilization. In this regard, some $25 \%$ of road cargo carriers in Europe and the U.S. run empty, which leads to a waste of billions of dollars in fuel (Matthams 2012). In addition, improved information helps to control the physical flow of goods and to reduce buffer inventories (Tanja and Ruijgrok 1990). However, the mentioned study in the automotive industry also indicates that a mere $20 \%$ of the companies have "knowledge of when shipments leave foreign ports; only $39 \%$ have knowledge of when goods clear US Customs [and] only $37 \%$ have knowledge of in-transit movement from customs” (Denno 2013, p. 617). While the sophistication of SC coordination differs considerably across industries - for instance, the average inventory turn in the consumer industry is 44 , whereas the automotive industry reports 10 and the healthcare industry just over two (Doone 
2014) - the main prerequisite for SC collaboration is transparency across all SC processes and involved parties. Referred to as SC visibility, physical activities occurring in a SC and the related management activities happening in the information (or virtual) domain are closely aligned. In this regard, important steps towards reducing SC inefficiencies already took place since the 1980s (McIntire 2014) with the standardization of communication protocols (e.g. TCP/IP), with the availability of standardized business messages (e.g. EDIFACT) and identification schemes (e.g. GTIN) as well as with the availability of multilateral electronic platforms.

These platforms have emerged in the last decades (see Alt and Zimmermann 2014, 162) as EDI clearing centers, logistics malls and electronic marketplaces. By creating centralized information hubs, they enabled the sharing of information among multiple actors along entire SCs. They were recognized as solutions to reduce SC inefficiencies and sharing data on status as well as event information led to SC visibility concepts, which in turn were attributed a positive impact on key performance metrics, such as cost, quality, service levels, flexibility and time (Caridi et al. 2014). At the same time, Caridi et al. (2014, p. 2) assert in their literature review that despite "the large number of articles, research on the benefits of visibility is still mainly theoretical".

\section{Research questions and methodology}

While standards-based solutions to share master and transactional data were introduced since the 1980s, the exchange of visibility data is relatively new. In this regard, the first release of the EPCIS specification (GS1 2014a), which is the basis of an increasing number of visibility services in practice and which is examined in this paper, was published in 2007. Hence, the total number of visibility service implementations as well as corresponding scientific publications in this area is still low. In most cases, the latter focus on organizations having implemented RFID (see e.g. Müller et al. 2009 and Tribowski et al. 2009). In view of these shortcomings, the present 
research analyzes implementations of a global SC visibility service, which follows an open approach and is capable of providing an arbitrary number of internal and external business applications with visibility data. It aims to identify the main design options and to shed light on the benefits in the field of SC visibility. In particular, three research questions shall be addressed:

(1) What are the main options for designing visibility services?

(2) How can visibility services be provided in heterogeneous networks?

(3) What are the key benefits of implementing visibility services?

As “...IS researchers (...) often find themselves trailing behind practitioners (...) [and] a case approach is an appropriate way to research an area in which few previous studies have been carried out” (Benbasat et al. 1987, p. 370), this paper pursues a case study approach to address these questions. Referring to Yin (2009, p. 46 ff.), it exerts a single-case design (pertaining to a globally applicable visibility service) with three embedded units ('type 2'). The rationale behind the single-case design consists in the representative nature of the unit of analysis (lack of competing standard specifications), which Yin (2009, p. 48) recognizes as one of five circumstances in which single-case studies are appropriate.

In one of the three implementations action research was applied. to obtain deeper insights in the design of a visibility service. Action research “... is increasingly recognized as a viable research strategy (...) [in IS]” (Blichfeldt and Andersen 2006, p. 3) and is especially characterized by “... the active and deliberate self-involvement of the researcher in the context of his/her investigation.” (McKay and Marshall 2000, p. 576). This strategy seemed particularly suited as it allowed to further test and refine earlier findings. It was possible to scrutinize the practical problem of designing a visibility service while its market penetration evolved regarding the number of users as well as industry sectors. Pilot projects, end user feedback, market requirements and technological change allowed for various cycles of action and reflection. 
The paper first explains the main terms together with the existing state of research. This is followed by a description of three implementations and a comparison of the observations in these case companies. Finally, the results are discussed with regard to design options for visibility services, operator models as well as potentials.

\section{Literature analysis}

In the academic literature, SC visibility has been recognized as an important enabler for SCM, which is conceived as "the systemic, strategic coordination of the traditional business functions and the tactics across these business functions within a particular company and across businesses within the supply chain, for the purposes of improving the long-term performance of the individual companies and the supply chain as a whole” (Mentzer 2001, p. 18). Without the availability of up-to-date information on the status of goods in a SC, planning adjacent activities and re-scheduling plans in the case of critical events would not be feasible. These events may be conceived as milestones along the SC, which require status information (Otto 2003) and the extraction of critical incidents that point to immediate action (Liu et al. 2007, p. 761f).

Managing these events has become known as SC event management (SCEM) and comprises the functionalities monitoring, notifying, simulating, controlling, and measuring (Nissen 2002). SC visibility is closely related to SCEM. For example, one functional cluster within SAP's SCM solution map besides network design and supply network collaboration is SC definition and visibility (Kurbel 2013, p. 274). This cluster includes the functionalities SC monitoring, SC analytics and sales \& operations planning, which indicates that visibility represents a basic functionality contributing to application areas, such as monitoring, analytics and planning.

The broad nature of SC visibility is also reflected in the literature, where a definition by Caridi et al. (2014, p. 2) conceives it as "the sharing of all relevant information between SC partners, even over echelons in the chain”. By adopting a single case study, Bartlett et al. (2007) show 
that sharing information on material ordering, inventory management and business performance forms the basis for closer forms of collaboration. Many benefits of SC visibility were reported in the literature, such as the above mentioned improvements in cost, quality, service levels, and time (Caridi et al. 2014). Wei and Wang (2010, p. 245) point out that SC visibility might also act "as a potential driver of competitive advantage in turbulent environments through dynamic capabilities”.

According to Marufuzzaman/Deif (2010, p. 484), today’s supply chains may be conceived as nonlinear dynamic systems which make it “...difficult for supply chain managers to clearly understand various problems in supply chain operations and make appropriate decisions in time.” In this regard, systems theory (Bertalanffy 2008, p. $103 \mathrm{ff}$.) is helpful in explaining both the need as well as the conceptual basis of SCEM applications (Tröger 2014, p. 23 f.; 42). Managing the growing complexity of supply chains may be accomplished by applying extended control loops encompassing both feedback and feedforward mechanisms (see Figure 1). Thereby, feedback is based on an ex-post variance analysis whereas feedforward constitutes an ex-ante anticipation of potential incidents (Schwaninger 2001, p. 1214 ff.). Both mechanisms require accurate and timely SC visibility data. Ideally, SC data is captured automatically and shared among SC parties in real-time. Following the research on the bullwhip effect, it creates a single signal for all SC participants and forms the basis for SCEM, which identifies critical events and determines adequate actions alternatives. SCEM in turn may be regarded as an enabler of more encompassing SCM concepts, such as just-in-sequence, that also comprise other activities, for instance network design and demand planning (Naslund and Williamson 2010). 


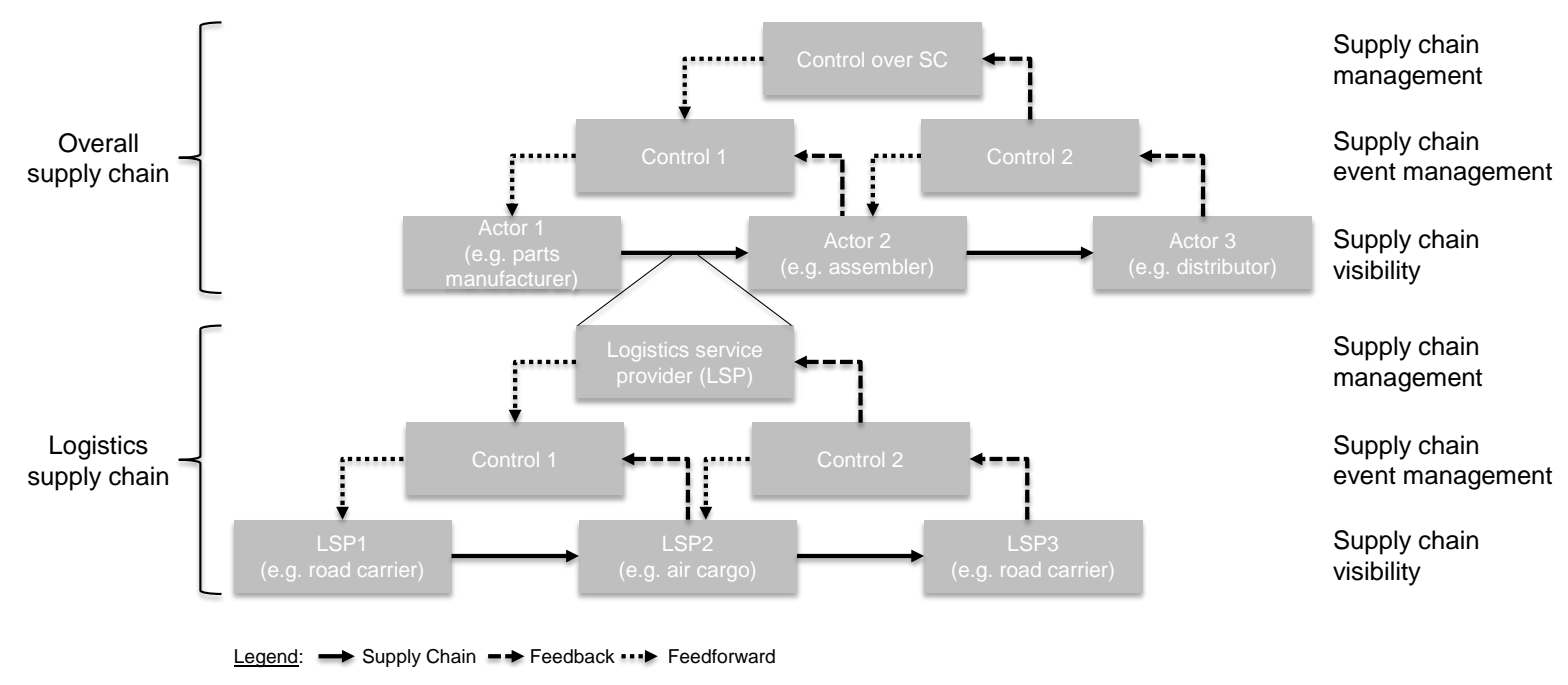

Figure 1: Supply chain visibility from a systems theory perspective

Obviously, SC visibility depends on the availability of an information infrastructure that links all parties in a SC. In view of the key role of information processing and sharing in SCM as well as the inefficiencies resulting from proprietary IS and messages, the use of information hubs has a long history in logistics. The above mentioned clearing centers already offered centralized functionalities and may be regarded as predecessors of electronic markets in logistics. They follow the dual relationship between electronic business and logistics (Alt et al. 2000), which recognizes logistics as an integral part of electronic commerce on the one hand (i.e. in the settlement phase) and as a platform for coordinating the information exchange among the actors in a logistics chain on the other. However, neither the functionalities of the individual actor's IS nor those of the electronic platform were standardized.

It was during the 2000s that the concept of service-oriented architectures (SOA) brought the idea of functional modules, which were able to interact within a defined broader architecture. These services were recognized as well-specified, self-contained, and reusable modules providing functionalities that are independently deployable via standardized interfaces (Alt et al. 2010). To coordinate these services, a SOA typically comprises a service directory, which con- 
tains service information in a standardized notion. Directories may be distinguished in repositories that contain the service descriptions themselves (e.g. in a UDDI structure) and registries, which only comprise an index and point to services. Besides the directory, a SOA also envisages service descriptions in standardized notation, as well as an integration platform (e.g. an enterprise service bus) that enables interoperability.

For example, a service registry may be operated by an electronic market provider, who offers services to SC parties. Together with event-driven concepts, so-called event-driven SOA were suggested, which have already shown their applicability in the area of logistics (Levina and Stantchev 2009). In addition, various other application architectures were suggested for SCEM (see e.g. Nissen 2002, Otto 2003, Speyerer and Zeller 2004, Zimmermann et al. 2006, Tribowski et al. 2009). However, these approaches focus on specific SCEM functionalities (particularly, they lack support as to simulate and control) and were mostly developed prior to the evolution of SOA (Tröger 2014, p. 87).

\section{EPCIS case study}

Service-orientation is based on the use of open standards, which foster the integration of application modules in the architecture of all SC participants. Apart from e.g. the World Wide Web Consortium (W3C) and the International Organization for Standardization (ISO), one of the major organizations to offer such standards worldwide is GS1. GS1 is a neutral, nonprofit and global organization providing standards, which are used by more than two million companies in various industries, especially fast-moving consumer goods (FMCG), healthcare, apparel/fashion/footwear, manufacturing as well as transport and logistics. By now, GS1 has grown to a network of about 112 national member organizations. (GS1 AISBL 2015, p. 2 ff.)

GS1 standards may be categorized in the layers identify, capture, and share (see Figure 2). While the first layer provides the means to identify business objects, such as products and logistics 
units, the second enables their automatic capture via barcodes and RFID. In this regard, the most widely known GS1 data carrier is EAN/UPC, which is applied at almost every consumer trade item and encodes the Global Trade Item Number (GTIN). The third layer pertains to the exchange of master, transaction and visibility data between trading partners.

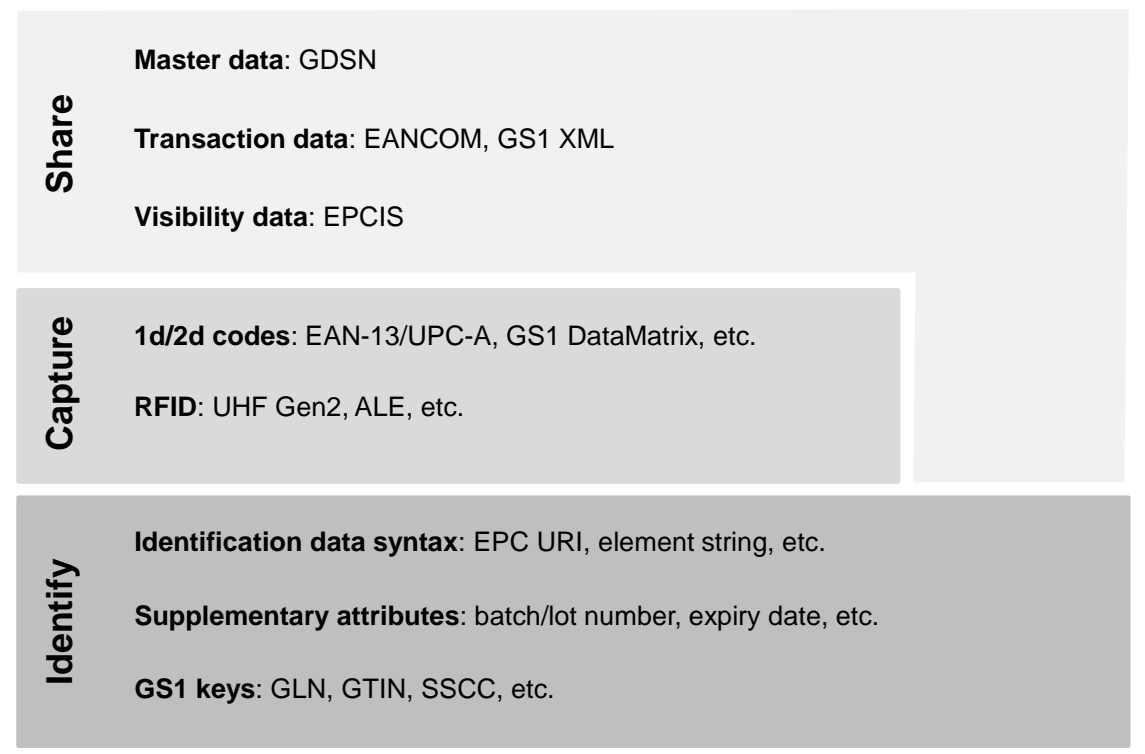

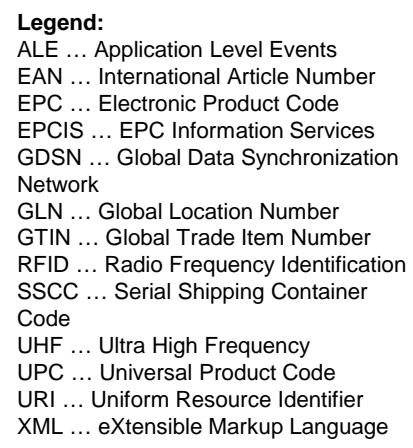

Figure 2: Overview on GS1 standards (GS1 2013, p. 12)

EPCIS is a specification provided by GS1 and ISO/IEC and belongs to the share layer of the GS1 system. It empowers applications to leverage visibility data both within as well as across companies and defines a standard interface for capture and query operations as well as an event data model. An EPCIS event comprises four dimensions (see Figure 3): what (one or several object identifiers), when (the time an event occurred), where (the business location) and why (the business context). Once an organization has identified its visibility goals, it may define its corresponding critical tracking events (CTE) and model them as EPCIS messages, e.g. by using a visibility data matrix as depicted in Figure 3. In this particular instance, it is assumed that one of an organization's CTEs is the shipping of logistics units. 


\begin{tabular}{|c|c|c|c|}
\hline Dim & Data Element & Contents & XML example (without document header) \\
\hline & Event Type & Object Event & \multirow{8}{*}{$\begin{array}{l}\text { <EventList> } \\
\text { <ObjectEvent> } \\
\text { < eventTime>2015-04-30T14:58:56.591Z</eventTime> } \\
\text { <eventTimeZoneOffset>+02:00</eventTimeZoneOffset> } \\
\text { <epcList> } \\
\quad \text { <epc>urn:epc:id:sscc:4012345.1111111111</epc> } \\
\text { </epcList> } \\
\text { <action>OBSERVE</action> } \\
\text { <bizStep>urn:epcglobal:cbv:bizstep:shipping } \\
\text { </bizStep> } \\
\text { <disposition>urn:epcglobal:cbv:disp:in_transit } \\
\text { </disposition> } \\
\text { <readPoint> } \\
\quad<\text { id>urn:epc:id:sgln:4012345.00001.0</id> } \\
\text { </readPoint> } \\
\text { </ObjectEvent> }\end{array}$} \\
\hline & Action & OBSERVE & \\
\hline What & EPC List & $\begin{array}{l}\text { SSCC identifying } \\
\text { logistics unit(s) }\end{array}$ & \\
\hline \multirow[t]{2}{*}{ When } & Event Time & Timestamp & \\
\hline & $\begin{array}{l}\text { Event Time Zone } \\
\text { Offset }\end{array}$ & $\begin{array}{l}\text { Local time } \\
\text { relative to UTC }\end{array}$ & \\
\hline Where & Read Point & $\begin{array}{l}\text { GLN identifying } \\
\text { goods issue area }\end{array}$ & \\
\hline \multirow[t]{2}{*}{ Why } & Business Step & Shipping & \\
\hline & Disposition & In transit & \\
\hline
\end{tabular}

Figure 3: Example of a visibility data matrix with corresponding EPCIS XML structure

Given the appropriate infrastructure (e.g. a barcode scanner) companies need to set up an EPCIS capturing application, which triggers an EPCIS event every time a logistics unit is captured (usually via HTTP Post). In this case, the EPCIS event accommodates the Serial Shipping Container Code (SSCC) identifying the logistics unit, the timestamp, the location as well as the business context, which is expressed by vocabulary elements defined in the Core Business Vocabulary (CBV), the accompanying data standard to EPCIS (GS1 2014b). In this context, the business step (“shipping”) and disposition (“in_transit”) values in the XML structure are defined in the CBV, which allows for an unambiguous interpretation by any business partner within the company's SC. Although the EPCIS standard also provides an AS2 (applicability state 2) binding, accessing applications typically make use of SOAP-based web services to invoke ad-hoc or standing queries (i.e. subscriptions that are triggered based on specific conditions and/or according to a predefined time schedule).

Many organizations have deployed SCEM applications, either by leveraging off-the-shelf solutions (offered e.g. by AXIT, LOG-NET, Manhattan Associates, SAP, Setlog, TXT, and Viewlocity) or via proprietary systems. As EPCIS supports to detect a multitude of critical SC events, especially regarding deviations as to product identity, quantity, location, quality and time (see 
Tröger 2014, p. 131 f.), a growing number of software vendors already offer EPCIS-based solutions (e.g. Axway, Frequentz, LG Hitachi, Microsoft, Samsung, SAP, and T-Systems). From a technical point of view, EPCIS provides open, standardized interfaces that allow for a seamless and cost-efficient integration in SOA environments. From a business perspective, it enables an in-depth and (if required) even real-time view in business processes. In this context, EPCIS event data may be utilized not only by SCM applications (e.g. SCEM and warehousing) but also beyond (e.g. controlling, retail management, product authenticity).

\begin{tabular}{|c|c|c|c|c|c|c|}
\hline \multirow[b]{2}{*}{ Data carrier usage } & \multicolumn{6}{|c|}{ Industry sector } \\
\hline & $\mathrm{T} \& \mathrm{~L}$ & Food & $\mathrm{TI}$ & AFF & Healthcare & Others \\
\hline No data carrier & & $x$ & $x$ & & & $x$ \\
\hline $1 d / 2 d$ codes & $x$ & $x$ & $x$ & $x$ & $x$ & $x$ \\
\hline RFID & $x$ & $x$ & $x$ & $x$ & & $x$ \\
\hline \multicolumn{7}{|c|}{$\begin{array}{l}\text { Legend: T\&L...Transport \& Logistics, TI...Technical Industries (including automotive), } \\
\text { AFF...Apparel/Fashion/Footwear }\end{array}$} \\
\hline
\end{tabular}

Table 1: Systematization of EPCIS implementations by industry and data carrier usage

Although the total number of EPCIS projects is unknown due to the lack of publicly available statistics, literature research and the authors’ personal knowledge of more than 100 implementations suggest that EPCIS usage depends on the industry sector and data carrier usage (see Table 1). For instance, the cross in column 'healthcare' refers to EPCIS implementations with healthcare firms whose products and logistics units are identified with either $1 \mathrm{~d}$ or $2 \mathrm{~d}$ codes. Each scan (at critical process steps such as manufacturing, packing, and shipping) of these codes triggers an EPCIS event supporting companies to e.g. fulfil legal traceability requirements, generate metrics or enable product authenticity checks.

From all implementations investigated by the authors, those cases were identified that offered more than one source of information as case study research asks for “...employing multiple 
methods of data collection (...)” (Benbasat et al. 1987, p. 369). Out of the remaining 14 implementations, three cases were selected that allowed for a cross-industry perspective and accommodated all means by which EPCIS events are triggered.

\begin{tabular}{|c|c|}
\hline Organization & Data collection method \\
\hline Deutsche Post DHL & $\begin{array}{l}\text { Semi-structured interviews } \\
\text { - Time/duration: June } 2011 \text { (ca. 45-60 minutes each) } \\
\text { - Interviewees: Senior Consultant, Project Manager } \\
\text { - Modality: on site (Düsseldorf, Germany), per telephone } \\
\text { Literature research }\end{array}$ \\
\hline ThyssenKrupp & $\begin{array}{l}\text { Semi-structured interview } \\
\text { - Time/duration: March } 2013 \text { (ca. } 90 \text { minutes) } \\
\text { - Interviewees: Head of Application Development, Project } \\
\text { Manager } \\
\text { - Modality: on site (Essen, Germany) } \\
\text { Literature research }\end{array}$ \\
\hline GS1 Germany & $\begin{array}{l}\text { Action research } \\
\text { - Time: } 2012 \text { to date } \\
\text { - Author's position: Senior Manager Identification/Data Carrier } \\
\text { - Modality: active member of fTRACE development team } \\
\text { (areas of responsibility: specification and implementation of } \\
\text { new functionalities/services/EPCIS infrastructure elements, } \\
\text { user support, industry engagement, etc.) } \\
\text { Literature research }\end{array}$ \\
\hline
\end{tabular}

Table 2: Research and data collection methods

As indicated in Table 2, the data collection methods were mainly literature research complemented with either semi-structured interviews or action research. Action research was conducted by one of the paper's authors, who is a long-term member of the development department with GS1 Germany and who conducted the semi-structured interviews (two on site, one via telephone). The answers to the questions (the guide can be found in the paper's appendix) were recorded in writing and approved by the informants before they were coded. In order to model 
the respective application architectures, ArchiMate 2.1 was used. ArchiMate is an Open Group standard that has become recognized as a reference graphical modeling language for enterprise architecture (Josey et al. 2013). The modeling elements used in the course of this paper are summarized in Figure 4.
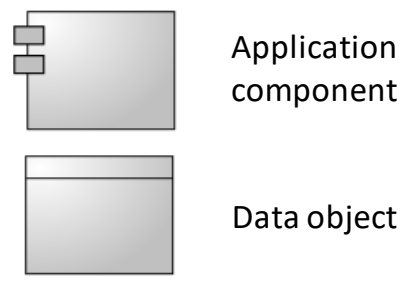
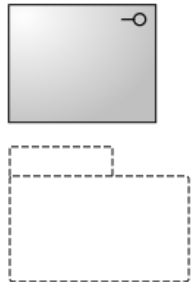

Application

interface

Grouping

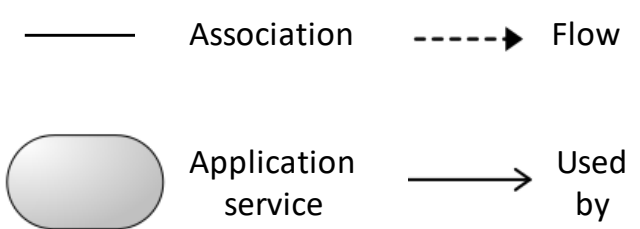

Figure 4: Notations used from ArchiMate 2.1

(a) Deutsche Post DHL

Deutsche Post DHL is a globally leading logistics service provider and uses EPCIS in a growing number of applications. The company first considered EPCIS in 2007/2008 during a multi-national and multi-stakeholder pilot project. The initiative demonstrated the applicability of EPCIS to enable interoperability among multiple trading partners, visibility of critical tracking events, and real-time information access for authorized business partners (GS1 EPCglobal 2009, Swedberg 2008).

After successfully completing the pilot, $D H L$ strived to leverage the identified benefits both for itself as well as for its customers. The first major solution which made use of EPCIS in a productive environment was implemented in warehouses in Shanghai and Hong Kong and triggered EPCIS event messages whenever critical process steps were accomplished. Applications for automatic identification and data capture (AIDC), such as barcode and RFID tunnel readers, automatically capture all shipment units and generate EPCIS events accommodating the object identifiers observed. Although the solution is still limited to serialized identifiers (either SSCCs on logistics labels or serialized GTINs on RFID tags applied at trade items), the EPCIS infrastruc- 
ture benefits both internal systems (e.g. warehouse management, data warehouse, EDI converter) and customers’ applications (see Figure 5). This enhances exception management, SC control as well as an improved planning of goods receipt. One of the first customers requiring the company's EPCIS data was Gerry Weber, a fashion company whose entire merchandise is equipped with RFID tags. Gerry Weber integrated its order management system to improve visibility on the status of production orders and shipments.

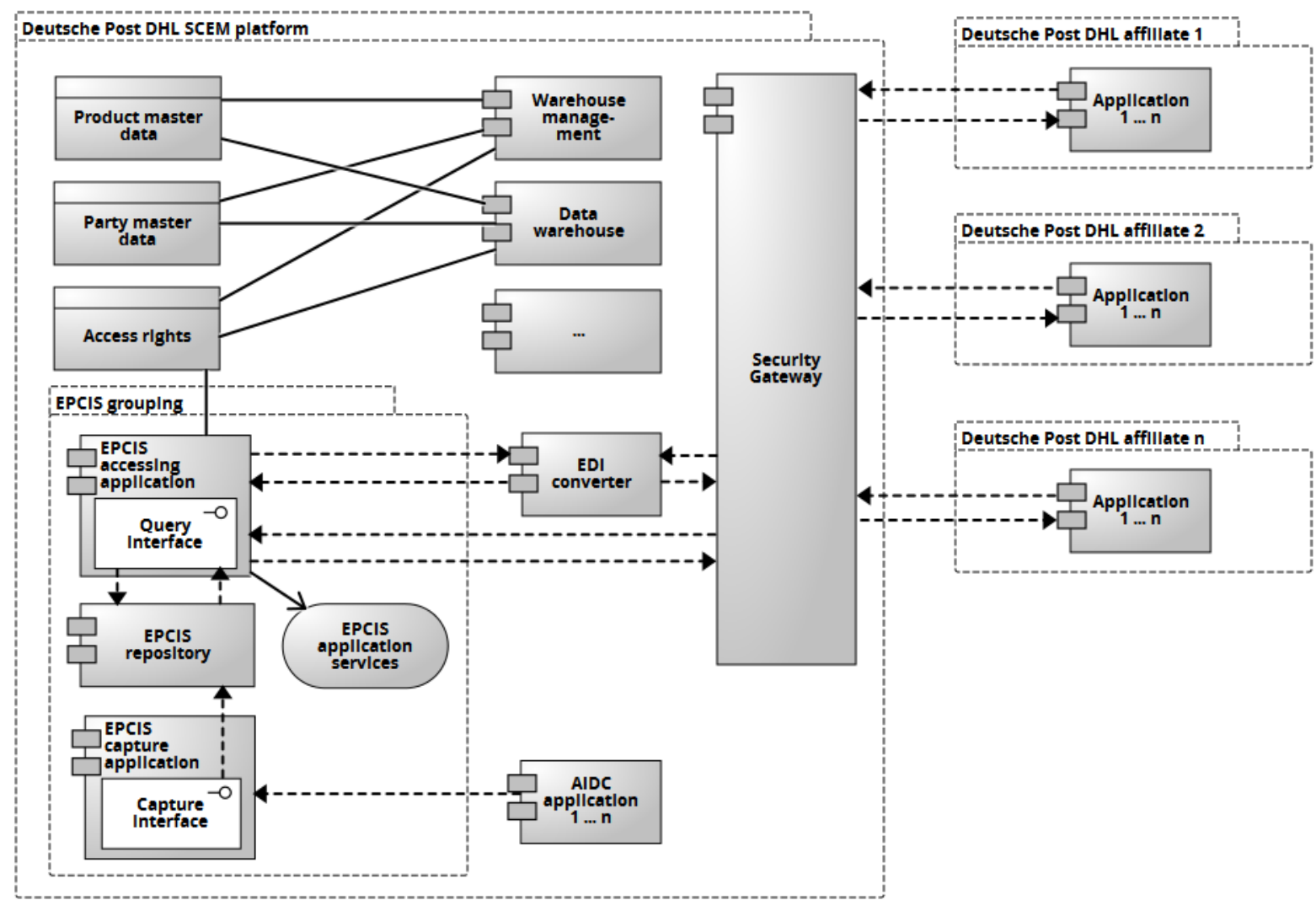

Figure 5: Implementation of EPCIS at Deutsche Post DHL

The case illustrates various benefits of EPCIS for logistics/transport service providers. First, it enables new value-added services, which may contribute to differentiation in the marketplace. Second, it substantiates the advantages of service-orientation as the company's EPCIS query service is used for several applications, thus leading to savings in time and cost both for Deutsche Post DHL as well as its affiliates. Although the company has not published any figures, the potential savings in development, quality assurance and integration costs are positive 
and support the findings by Assman et al. (2010, p. $116 \mathrm{ff}$.). According to their research a service which is used by five applications saves a company $50 \%$ in development costs, $80 \%$ in costs for maintenance and debugging as well as $90 \%$ in integration costs compared to a separate implementation in all five IS.

(b) ThyssenKrupp

Another pioneer in the usage of EPCIS is ThyssenKrupp (Wessel 2007). Originally, the company aimed to leverage the potentials of RFID (e.g. acceleration of processes, reduction of mistakes, and improvement of stock transparency) in handling more than 2,000 grades of steel. After the implementation of the underlying EPCIS infrastructure, the organization - confronted with a growing cost pressure - recognized additional potentials especially as to increased SC control and efficiency.

In the following, the company has implemented an SCEM platform, which is based on an EPCIS repository containing all relevant visibility events of each steel slab. These steel slabs are identified with RFID tags (encoding serialized GTINs) and captured at various RFID read points along the company's SC. Once a critical process step (e.g. commissioning, shipping, and receiving) is accomplished, the AIDC application triggers an EPCIS event. Similar to Deutsche Post DHL, several internal applications use the EPCIS query interface and make the information accessible to business partners. SCEM-relevant applications encompass a SC visualizer, an alert engine as well as a key performance indicator (KPI) dashboard (see Figure 6). This allows notifying process owners proactively once defined lead-time thresholds are exceeded or in case process gaps occur. ThyssenKrupp especially benefits from the real-time capability of EPCIS and reports an improved overall SC performance (Hesse 2013). 


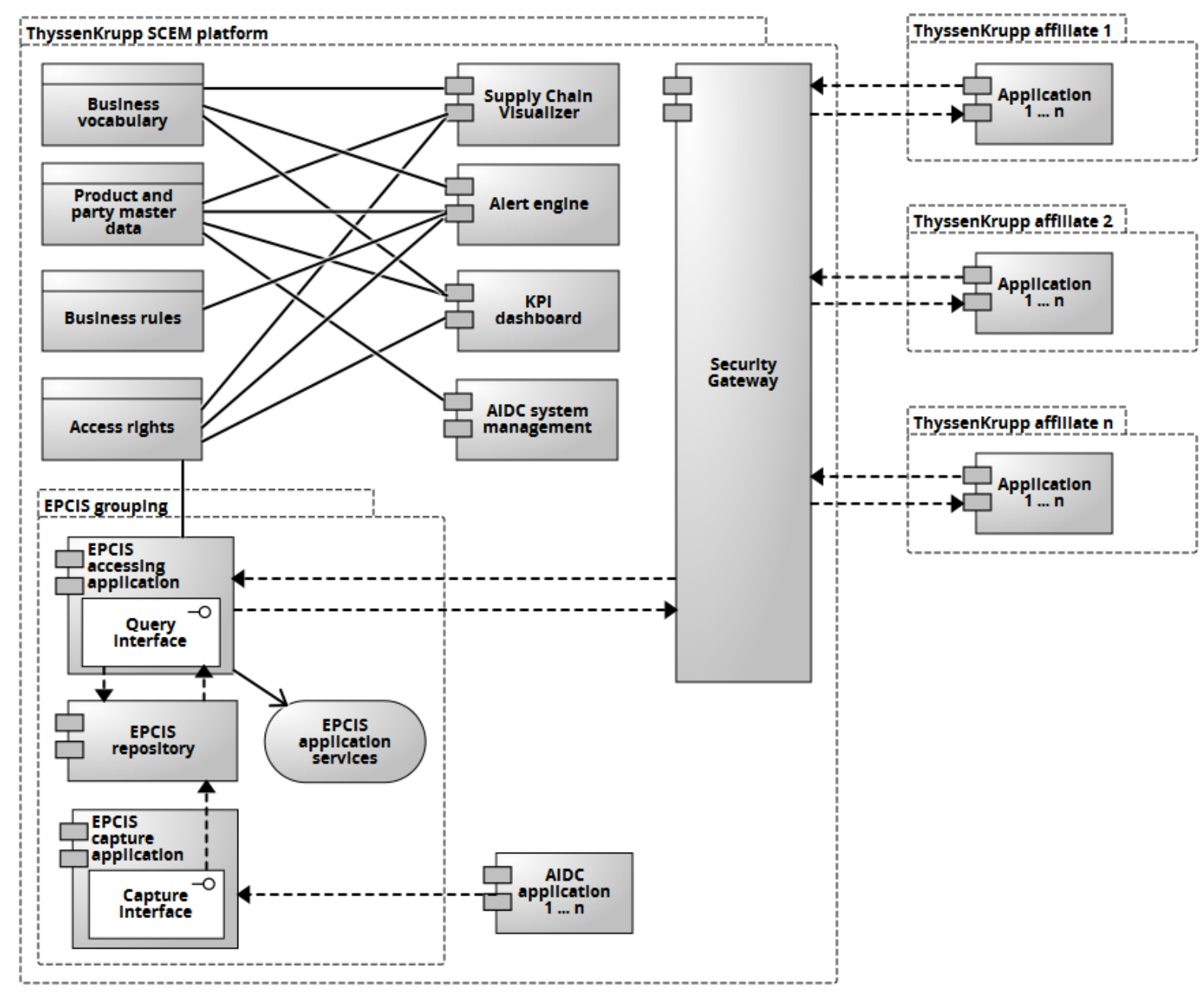

Figure 6: Implementation of EPCIS at ThyssenKrupp

Similar to the first implementation example, the SCEM platform realized by ThyssenKrupp also reveals SOA benefits. This is due to the standardized interface as well as the common syntax and semantics of EPCIS event messages, which allow for an efficient integration in an arbitrary number of internal and external business applications. Consequently, the company plans to extend the SCEM platform's range of functions and to expand it to other product categories.

\section{(c) GS1 Germany}

The third implementation example is fTRACE, an EPCIS- and cloud-based traceability platform provided by GS1 Germany. It offers organizations a neutral as well as scalable tracking and tracing solution that enables SC partners to capture and exchange traceability data in a growing 
number of sectors (e.g. fish, meat, fresh fruits and vegetables). All dynamic data generated along the SC (e.g. harvesting, processing, shipping) is captured and shared via EPCIS event messages, which - in contrast to the former cases - are typically not populated with instance-level, but class-level identifiers (i.e. GTIN and batch/lot number). The service does not necessarily require centralized data hosting, thus allowing each SC party to provide visibility data by means of an own EPCIS repository as well.

fTRACE helps companies to comply with traceability regulations and/or their customer's requirements. It offers an increasing number of business services (e.g. query for origin information, query for products in transit, query for traceability trees), which are relevant both in business-to-business (B2B) as well as business-to-government (B2G) applications. A rights management service ensures that only authorized organizations may access the data they request. It also offers a business-to-consumer (B2C) front-end, which allows consumers to obtain traceability data for a given product batch/lot (see Figure 7).

The case example illustrates the benefits of cloud-based solutions. Most importantly, even small companies are enabled to provide and access visibility data via web interfaces. The system also features scalability, both in terms of additional future product categories (e.g. timber and tobacco) as well as in terms of its global applicability. Another advantage consists in the one-off development and maintenance costs. A common standard replaces bilateral interfaces and reduces communication costs with other SC participants. The cloud solution fosters vendor independence as each organization may implement an own EPCIS repository or opt for a solution offered by a third-party provider (as long as the latter are compliant to the standard). Another advantage is the simple billing model: companies only need to pay a one-off origination fee as well as an annual lump sum. Although the focus of fTRACE is on traceability, the service may also be utilized for SCEM: as soon as its affiliates have granted the necessary access rights, a 
company may benefit both from its own as well as from the visibility data captured by its business partners (such as production, packing and goods issue).

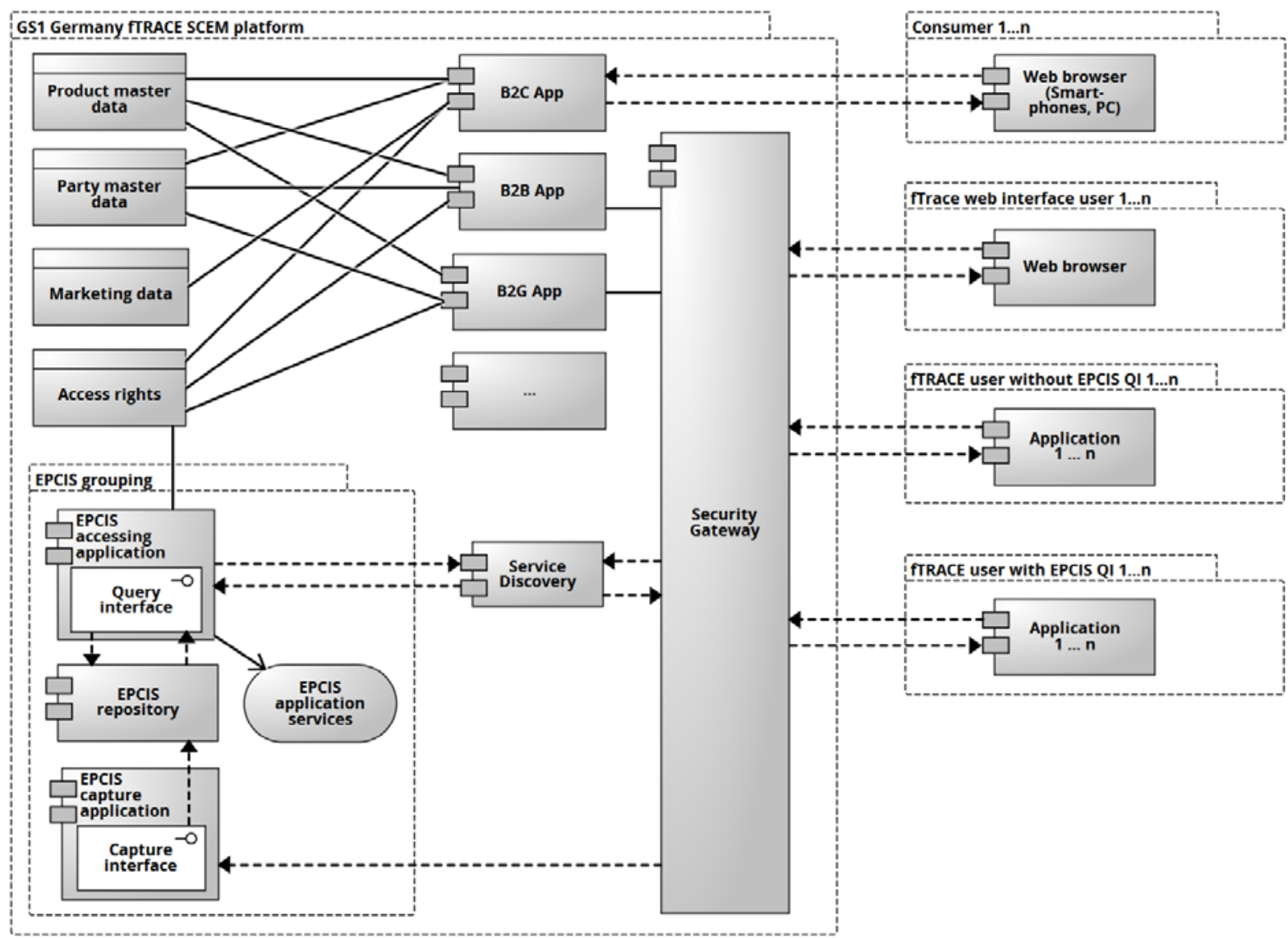

Figure 7: Implementation of EPCIS at GS1 Germany

\section{Discussion and findings}

The material originating from the semi-structured interviews and action research was coded according to the strategy recommended by Schmidt (2004, $253 \mathrm{ff}$.), while the fifth and last step (i.e. selecting individual cases for an in-depth single-case analysis) was not required for the purpose of this paper.

The first step consisted in identifying appropriate categories related to the context of the three research questions. For instance, as the method to transfer EPCIS events to business applications differed in part between the case companies, the 'query mode' was added to the list of analytical 
categories. In a second step, the draft categories were assembled into a guide containing the respective categories along with their characteristics. Taking the example of 'query mode', organizations have two main options: pull (involving a request/response mechanism) and push (either by setting up a subscription or by sending data based on a previously agreed pattern). The third step constituted the actual coding, i.e. the classification of the material while using the formerly developed coding guide. Sticking to the example used above, the records were scrutinized as to how internal or external applications are provided with visibility data. The fourth step consisted in compiling and presenting the coding results. For instance, the 'query mode' was one out of seven criteria used to illustrate the design options for an EPCIS-based visibility service in the form of a table (see Figure 8).

Overall, the three EPCIS implementations yield insights in three areas. First, each service implementation reveals different design options and operator models while the latter were recognized as a second design option. Third, the samples underpin the potentials of a service-oriented application design in general and EPCIS as the basis of visibility applications in particular.

\section{(a) Design options}

Following the nature of the EPCIS standard, multiple implementations of the visibility service are feasible. They differ regarding criteria, which may be conceived as design and configuration options. Figure 8 summarizes the design options that were observed in the three selected implementations. For example, the fTRACE platform offers customers a cloud-based solution that supports both instance- and class level identification (e.g. product batch and logistics unit identification), operates with a centralized as well as with a distributed message choreography (in the latter case, third party EPCIS repositories are integrated with a discovery service), leverages both push and pull queries, utilizes visibility data for tracking, tracing, checking, and analysis, makes use of three out of four of the available EPCIS event types, and is usually provided with 
EPCIS events that are triggered through manufacturing execution systems, data entry websites, or barcode reader applications.

\begin{tabular}{|c|c|c|c|c|c|c|c|}
\hline Criteria & \multicolumn{7}{|c|}{ Characteristics } \\
\hline $\begin{array}{l}\text { Hosting/ } \\
\text { operation }\end{array}$ & \multicolumn{3}{|l|}{$\begin{array}{l}\text { Local } \\
(D, T)\end{array}$} & \multicolumn{4}{|c|}{$\begin{array}{l}\text { Cloud } \\
\text { (G) }\end{array}$} \\
\hline $\begin{array}{l}\text { Granularity of } \\
\text { identification }\end{array}$ & \multicolumn{3}{|c|}{$\begin{array}{l}\text { Instance-level identification } \\
(D, G, T)\end{array}$} & \multicolumn{4}{|c|}{$\begin{array}{l}\text { Class-level identification } \\
\text { (G) }\end{array}$} \\
\hline Choreography & \multicolumn{2}{|l|}{$\begin{array}{l}\text { Centralized } \\
\text { (G) }\end{array}$} & \multicolumn{3}{|c|}{$\begin{array}{l}\text { Distributed query } \\
(G, T)\end{array}$} & \multicolumn{2}{|c|}{$\begin{array}{l}\text { Distributed push } \\
\text { (D) }\end{array}$} \\
\hline Query mode & \multicolumn{3}{|l|}{$\begin{array}{l}\text { Pull } \\
(G, T)\end{array}$} & \multicolumn{4}{|c|}{$\begin{array}{l}\text { Push } \\
(D, G, T)\end{array}$} \\
\hline $\begin{array}{l}\text { Generic use } \\
\text { case }\end{array}$ & $\begin{array}{l}\text { Tracking } \\
(\mathrm{G}, \mathrm{T})\end{array}$ & $\begin{array}{l}\text { Tracing } \\
(D, G, T)\end{array}$ & \multicolumn{2}{|c|}{$\begin{array}{l}\text { Analysis } \\
(D, G, T)\end{array}$} & \multicolumn{2}{|c|}{$\begin{array}{l}\text { Checking } \\
(G, T)\end{array}$} & $\begin{array}{l}\text { Automation } \\
(D, T)\end{array}$ \\
\hline $\begin{array}{l}\text { EPCIS event } \\
\text { type }\end{array}$ & \multicolumn{2}{|l|}{$\begin{array}{l}\text { Object } \\
(\mathrm{D}, \mathrm{G}, \mathrm{T})\end{array}$} & $\begin{array}{l}\text { Aggregation } \\
(D, G)\end{array}$ & \multicolumn{3}{|c|}{ Transaction } & $\begin{array}{l}\text { Transformation } \\
\text { (G) }\end{array}$ \\
\hline $\begin{array}{l}\text { Data capture } \\
\text { infrastructure }\end{array}$ & \multicolumn{2}{|c|}{$\begin{array}{l}\text { RFID reader software } \\
(D, T)\end{array}$} & \multicolumn{3}{|c|}{$\begin{array}{l}\text { Barcode reader software } \\
(D, G, T)\end{array}$} & \multicolumn{2}{|c|}{$\begin{array}{l}\text { Other (e.g. ERP system) } \\
\text { (G) }\end{array}$} \\
\hline
\end{tabular}

Figure 8: Design options of an EPCIS-based visibility service

The above overview might serve practitioners as decision support in setting up visibility applications. Taking the example of the design option 'granularity of identification', an accessing application would not be able to determine the chain of custody if individual participants of the same SC modelled their EPCIS events on instance-level while others chose class-level identification. In this regard, it is important that business partners agree on common identification schemes (e.g. GTINs and SSCCs) to enable scalability. Consistency on these matters (along with other important issues such as the message choreography, the usage of extension elements, etc. which may impair interoperability) can typically be achieved by the negotiation power of focal companies, such as ThyssenKrupp, or by an industry consensus moderated by a neutral party, such as GS1. 
(b) Operator models

Within a SOA, EPCIS capture and query services may be considered as application services, which interact with other services. Application services are based on more basic IT services and may be orchestrated to more complex business services (Kohlmann and Alt 2009, p. 204). For instance, an EPCIS query service may be aggregated to an arbitrary number of business services, e.g. quantity variance control, delivery time control, process and/or status monitoring, as well as the provision of reports and/or key performance indicators. Applied to the fashion industry, a SCEM service architecture might encompass a set of 27 business services (Tröger 2014, p. 91 ff.).

As mentioned above, the design of the service directory is another element of a SOA. Since visibility services are inherently distributed in SC networks, business partners require efficiency in identifying and binding the indexed services. Among the established alternatives are centralized, hybrid, or decentralized models. As both purely centralized and decentralized models are associated with disadvantages (see Akolkar et al. 2012, p. 263; Sellami et al. 2011, p. 230; Pilioura and Tsalgatidou 2009, p. 11:2), hybrid approaches seem to be best suited (Kouki and Ledoux 2012; Sellami et al. 2011, p. 231; Pilioura and Tsalgatidou 2009, p. 11:3 f.; Kassim et al. 2007, 311 ff.). For example, a centralized service registry operated by a visibility service provider might interact with decentralized service repositories of the respective business partners.

Figure 9 depicts the generic architecture for organizations, such as Deutsche Post DHL and ThyssenKrupp, who prefer to store their visibility data locally. While both companies share the description of their EPCIS query services with their affiliates on a bilateral basis, it presumes that visibility services (along with other services) are indexed in a service registry provided by a third party. Thus, the services can be discovered and integrated by business applications (e.g. for SCEM). 


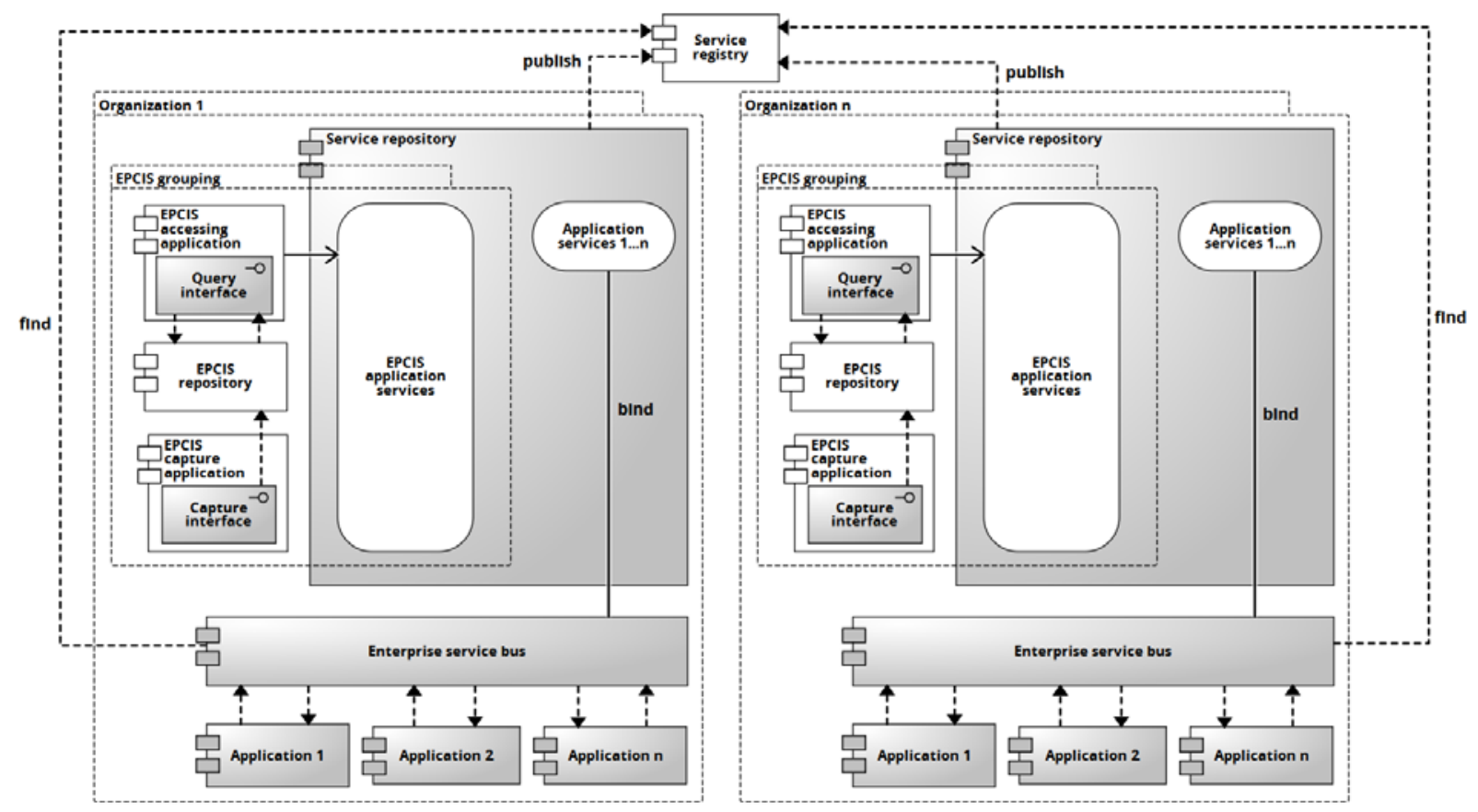

Figure 9: Generic architecture for locally hosted visibility applications/services

Although SOA solutions are spreading, local service repositories will eventually not be operated by all SC parties. In particular, SOA maturity is low in many small and medium enterprises (Computer Economics 2007, p. 4 f.) and also varies across industry sectors (e.g. insurance, retail and banking companies are regarded as early SOA adopters (Luthria and Rabhi 2012, p. 48; Computer Economics 2007, p. 5 ff.)). Hosted solutions based on cloud computing technology address this deficit and enable scalable, flexible and usage-based provisioning of IT resources and services (Pelzl et al. 2013; Böhm et al. 2011). In the cloud model, business partners without local service repositories may use cloud-based, multi-client capable Software-as-a-Service (SaaS) solutions (such as fTRACE, provided by GS1 Germany). While services may be re-used by many SC participants, developing, operating and maintaining these services is managed by the SaaS provider.

In case cloud providers also operate the ERP (enterprise resource planning) system of a SC participant, the required data relevant for SCEM-specific services (e.g. order, inventory, party 
and product master data) is already available on the platform. Users of cloud-based ERP solutions provided e.g. by Actindo, myfactory, Sage, Scopevisio, weclapp or work4all (Wyllie 2013) may configure their solution from a comprehensive portfolio of services, such as warehouse management, controlling, customer relationship management, distribution, procurement, financing, inventory management, production planning and control (PPC), quality management, sales and distribution. By offering additional SCEM services, cloud ERP providers may obtain a competitive advantage over their competitors and increase their revenues compared to traditional business models due to various consulting, migration, and integration services as well as the transaction revenues from using these services (e.g. Wyllie 2013). Within a cloud setting (see Figure 10), two organizations might use selected modules offered by the cloud ERP system provider, while another - in this case, the value chain integrator - still uses its own system components.

Irrespective of the chosen implementation (local vs. cloud-based), both architectures reflect the composition of EPCIS-based visibility services as inferred from the EPCIS implementations at Deutsche Post DHL, ThyssenKrupp and GS1 Germany. Fine-granular IT services that are typically covered by an EPCIS repository, an EPCIS capture (or query) interface, and an EPCIS capture (or accessing) application, are aggregated to EPCIS capture (or query) services, which may then be discovered and integrated by internal or external services and visibility applications. 


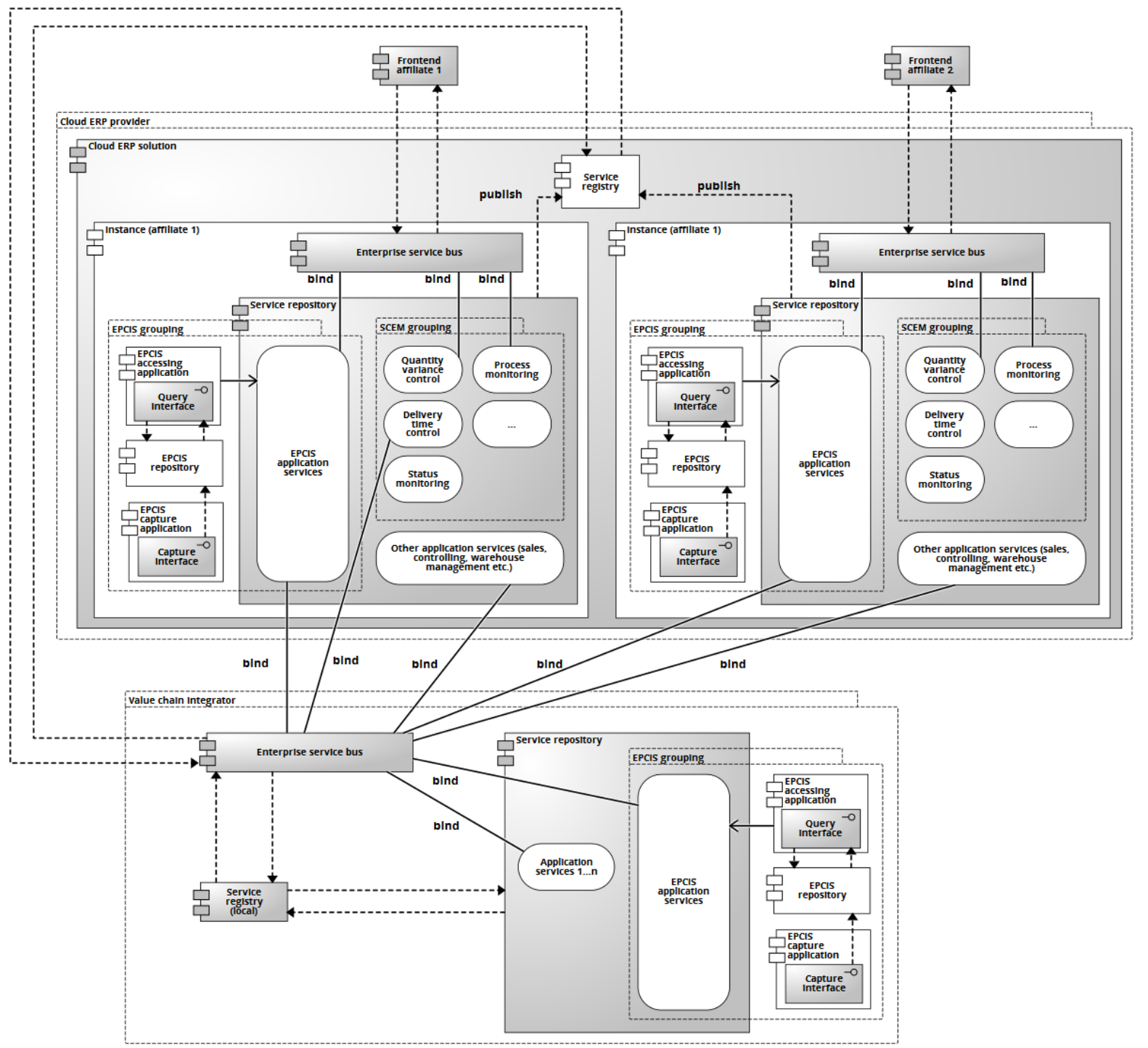

Figure 10: Extended architecture incorporating cloud-based visibility applications/services

(c) Potentials

The case study underpins major functional advantages of EPCIS-based visibility services for applications requiring visibility data (such as SCEM) and illustrates advantages of a serviceoriented design for SCEM solutions as outlined above. In terms of reutilization, one major advantage of applying SOA design principles, Jens Kungl (Senior Expert at Metro Group, which belongs to the early adopters of fTRACE), reports: "It can be utilized not only for traceability purposes, but also for internal process optimization for more targeted recalls, in-stock and supply chain management, anti-counterfeiting solutions, and fraud protection.” Further, Heiner 
Niehues (Head of Application Development at ThyssenKrupp) confirms its efficiency and flexibility: "From a technical point of view, the value added of EPCIS especially consists in the lower development and operating costs, the fast applicability to new use cases and the low complexity.”

In the domain of SCM, the observed potentials of implementing EPCIS-based visibility services may be summarized as follows (exact figures are omitted for confidentiality reasons): (a) ability to disclose numerous SC events, especially related to object identity, quantity, location, quality and time, (b) real-time availability of visibility data by setting up event- or time-triggered standing queries, (c) easy data filtering/selection of e.g. location, product, affiliate or business process, (d) profound basis for KPIs and SC simulations due to accurate as-is/historic data, (e) automated triggering of business processes such as the notification of a process owner, and (f) reproduction of an object's life cycle.

In general, both technical and business-related benefits may also be applicable to other domains, such as CRM, warehouse management, and controlling. Apart from its inherent scalability and flexibility, an adoption of an open standard, such as EPCIS, also diminishes the risk of a vendor lock-in.

In comparison to previous work, the three areas proposed above promise to extend existing research. For instance, this study takes into account several design options of EPCIS-based visibility services whereas e.g. Tribowski et al. (2009, p. 494 ff.) focus on the quantitative comparison of a centralized/pull-based vs. a decentralized/push-based architecture approach. The present paper also addresses the concern that there are still “... wide variations in visibility solutions [and] no visibility standards in the industry (...)” (McIntire 2014, p. 124). In addition, the revealed benefits of EPCIS-enhanced visibility applications are based on actual implementations whereas other papers mainly relied on simulations (see e.g. Müller et al. 2009, p. 145 ff.). Thus, this study also contributes to overcome the issue that “... visibility services become something 
which can lose the large customer, but can never win the customer or extract higher revenue” (McIntire 2014, p. 125).

\section{Conclusions}

This paper was motivated by the need for visibility services that enable increasingly complex SCs regarding specialization and dynamic performance. Electronic markets may be conceived as an enabler for implementing visibility services, which are used by multiple SC participants and which enable a real time view into SC member's processes in a syntactical and semantical uniform manner. In fact, the specialization in many SCs might correlate with a specialization of functionalities in the underlying application architectures. SOA principles, such as a common service specification, service abstraction, and the use of open standards, allow to define standardized modules, which may be integrated in many SC(E)M solutions. The example of the EPCIS visibility service was used since EPCIS has seen a growing adoption in diverse industry sectors and has also been implemented by various major software vendors. Based on three EPCIS implementations, seven main design elements for visibility services were identified together with a confirmation of the main SOA benefits.

Among the findings are that on the one hand, visibility services may be reused by multiple parties and that these services may also be configured to reflect the changing characteristics of SCs on the other. For example, visibility data may be collected for various types of events either on instance- or on class-level. This data may be captured via various technological infrastructures and shared in a more or less centralized (choreography) or active (query mode) fashion. The design elements are inter-related since data volume will increase with an instance-level granularity and multiple use cases as well as event types. In addition, the cases yield insight into the operation models. While the implementation of a local infrastructure might be feasible for 
large businesses, a cloud-based model offers further advantages especially for smaller companies. The more visibility applications are realized and reused following the cloud-based model, the more overall development efforts and the proliferation of individual service repositories may be reduced. Although the data volume in all three implementations was below the terabyte threshold, a cloud-based approach could allow for the flexible, demand-driven employment of additional resources once an organization is confronted with a growing data volume and/or velocity. Especially in the case of fTRACE, the quantity of EPCIS events is growing progressively with the growing number of companies and industry sectors. In this respect, it could be interesting to see the application of big data technologies, which could not only help to identify critical events from visibility data, but also to forecast and simulate future events.

Of course, these findings are limited due to the single-case study design of this study. Data from other visibility service implementations could not only help to verify the design options and the architectural patterns, but also to deepen the understanding of how visibility service implementations differ across industries. In addition, more quantitative studies would deepen the understanding of the advantages of cloud-based solutions as well as the time-, cost- and quality-related benefits of enhanced SC visibility.

\section{References}

Akolkar, R., Chefalas, T., Laredo, J., Perng, C.-S., Sailer, A., Schaffa, F., Silva-Lepe, I., \& Tao, T. (2012). The future of service marketplaces in the cloud. In: Proceedings IEEE $8^{\text {th }}$ World Congress on Services.

Alt, R., Abramowicz, W. \& Demirkan, H. (2010). Service-orientation in electronic markets. Electronic Markets, 20 (3-4), pp. 177-180. 
Alt, R., Grünauer, K. M. \& Reichmayr, C. (2000). Interaction of electronic commerce and supply chain management - Insights from 'The Swatch Group'. In: Proceedings $33^{\text {rd }}$ Hawaii International Conference on System Sciences (HICSS).

Alt, R. \& Zimmermann, H.-D. (2014). Editorial 24/3: Electronic markets and general research. Electronic Markets, 24 (3), pp. 161-164.

Assmann, M., Haack, M., Hagen, N.v., Schneider, H. \& Zacharias, R. (2010). SOA business case. In: Keuper, F., Hamidian, K., Verwaayen, E. \& Kalinowski, T. (Eds.). transformIT Optimale Geschäftsprozesse durch eine transformierende IT. Gabler, Wiesbaden, pp. 97-125.

Bartlett, P.A., Julien, D.M. \& Baines, T.S. (2007). Improving supply chain performance through improved visibility. The International Journal of Logistics Management, 18 (2), pp. 294-313.

Benbasat, I., Goldstein, D.K., Mead, M. (1987). The case research strategy in studies of information systems. MIS Quarterly, 11 (3), pp. 369-386.

Bertalanffy, L. (2008). An outline of general system theory. E:CO, 10 (2), pp. 103-123.

Blichfeldt, B.S. \& Andersen, J.R. (2006). Creating a wider audience for action research: Learning from case-study research. Journal of Research Practice, 2(1), Article D2.

Böhm, M., Leimeister, S., Riedl, C. \& Krcmar, H. (2011). Cloud computing: Outsourcing 2.0 or a new business model for IT provisioning? In: Keuper, F., Oecking, C. \& Degenhardt, A. (Eds.). Application management. Gabler, Wiesbaden, pp. 31-56.

Caridi, M., Moretto, A., Perego, A. \& Tumino, A. (2014). The benefits of supply chain visibility: a value assessment model. International Journal of Production Economics, 151 (12), pp. 119.

Computer Economics (2007). Service-oriented architecture: adoption trends in 2007. Computer Economics, 29 (2), February 200. 
Davenport, T.H. \& Short, J.E. (1990). The new industrial engineering: information technology and business process redesign. Sloan Management Review, 31 (4), pp. 11-27.

Denno, P. (2013). Trade collaboration systems. In: IRMA (Ed.). Supply chain management: concepts, methodologies, tools, and applications. IGI, Hershey (PA), pp. 615-633.

Doone, R. (2014). How supply chain management can help to control health-care costs. In: CSCMP’s Supply Chain Quarterly, 8 (3), http://www.supplychainquarterly.com/topics/ Logistics/20141110-how-supply-chain-management-can-help-to-control-health-care-costs (accessed on 08.11.2015).

GS1 AISBL (2015). Annual report 2014-2015, http://www.gs1.org/docs/annual_report/ GS1_Annual_Report_2015.pdf (accessed on 31.10.2015).

GS1 (2014a). GS1 EPC information services (EPCIS) version 1.1 specification. May 2014.

GS1 (2014b). Core business vocabulary (CBV) version 1.1 standard. May 2014.

GS1 (2014c). The GS1 system architecture, issue 2.0. March 2013.

GS1 EPCglobal (2009). Transportation and logistics phase 3 pilot program demonstrates that EPC/RFID technology based upon GS1 EPCglobal standards works in a real live environment, http://www.gs1.org/sites/default/files/docs/media_centre/gs1_pr_280409_epcglobal _tls_3.pdf (accessed on 29.03.2013).

Hesse, S.J. (2013). Ereignisbasiertes SCM bei ThyssenKrupp; VDP-Workshop RFID in der Papierindustrie. Sulzbach, March 2013.

Josey, A., Else, S., Franken, H., Jonkers, H., Band, I., Quartel, D., Parker, S., \& Homan, P. (2013). ArchiMate 2.1 - A pocket guide. The Open Group, Reading. 
Kassim, A., Esfandiari, B., Majumdar, S. \& Serghi, L. (2007). A flexible hybrid architecture for management of distributed web service registries. In: Proceedings $5^{\text {th }}$ Annual Conference on Communication Networks and Services Research (CNSR).

Kohlmann, F. \& Alt, R. (2009). Business-oriented service design in practice - learnings from a swiss universal bank. In: Proceedings $1^{\text {st }}$ International Symposium on Service Sciences (ISSS), Berlin.

Kouki, Y. \& Ledoux, T. (2012). SLA-driven capacity planning for cloud applications. In: Proceedings International Conference on Cloud Computing Technology and Science (CloudCom), pp. 135-140.

Kurbel, K.E. (2013). Enterprise resource planning and supply chain management. Springer, Berlin/Heidelberg.

Lambert, D., García-Dastugue, S. \& Croxton, K. (2005). An evaluation of process-oriented supply chain management frameworks. Journal of Business Logistics, 26, (1), pp. 25-51.

Lee, H.L, Padmanabhan, V. \& Whang, S. (1997). Information distortion in a supply chain: the bullwhip effect, in: Management Science, 43 (4), pp. 546-558.

Levina, O. \& Stantchev, V. (2009). Realizing event-driven SOA. In: Proceedings $4^{\text {th }}$ International Conference on Internet and Web Applications and Services (ICIW), pp. 37-42.

Liu, R., Kumar, A. \& van der Aalst, W. (2007). A formal modeling approach for supply chain event management. Decision Support Systems, 43 (3), pp. 761-778.

Luthria, H. \& Rabhi, F.A. (2012). Service-oriented architectures: myth or reality? IEEE Software, 29 (4), pp. 46-52. 
Marufuzzaman, M. \& Deif, A.M. (2010). A dynamic approach to determine the product flow nature in apparel supply chain network. International Journal of Production Economics, 128 (2), pp. 484-495

Matthams, R. (2012). Despite high fuel prices, many trucks run empty. In: The Christian Science Monitor, http://www.csmonitor.com/Business/2012/0225/Despite-high-fuel-prices-manytrucks-run-empty (accessed on 08.11.2015).

McIntire, J. S. (2014). Supply chain visibility: From theory to practice. Gower Publishing, Farnham.

McKay, J. \& Marshall, P. (2000). Rethinking current conceptualisations of action research. In: Proceedings of the Pacific Asia Conference on Information Systems (PACIS), paper 44.

McLaren, T., Head, M. \& Yuan, Y. (2002). Supply chain collaboration alternatives: understanding the expected costs and benefits. Internet Research: Electronic Networking Applications and Policy, 12 (4), pp. 348-364.

Mentzer, J. T., DeWitt, W., Keebler, J. S., Min, S., Nix, N. W., Smith, C. D. \& Zacharia, Z. G. (2001). Defining supply chain management. Journal of Business Logistics, 22 (2), pp. 1-25.

Müller, J., Tröger, R., Alt, R., Zeier, A. (2009). Gain in transparency vs. investment in the EPC network - analysis and results of a discrete event simulation based on a case study in the fashion industry. In: Proceedings $7^{\text {th }}$ International Joint Conference on Service Oriented Computing, pp. 145-155.

Naslund, D. \& Williamson, S. (2010). What is management in supply chain management? - A critical review of definitions, frameworks and terminology. Journal of Management Policy and Practice, 11 (4), pp. 11-28.

Nissen, V. (2002): Supply chain event management. Wirtschaftsinformatik, 44 (5), pp. 477-480. 
Otto, A. (2003). Supply chain event management: Three perspectives. The International Journal of Logistics Management, 14 (2), pp. 1-13.

Pelzl, N., Helferich, A. \& Herzwurm, G. (2013). Wertschöpfungsnetzwerke deutscher CloudAnbieter. HMD - Praxis der Wirtschaftsinformatik, 50 (292), pp. 42-52.

Pilioura, T. \& Tsalgatidou, A. (2009). Unified publication and discovery of semantic web services. ACM Transactions on The Web, 3 (3), pp. 11:1-11:44.

Schmidt, C. (2004). The analysis of semi-structured interviews. In: Flick, U., Kardorff, E., \& Steinke, I. (Eds.). A companion to qualitative research. Sage, London et al., pp. 253-258.

Schwaninger, M. (2001). System theory and cybernetics: A solid basis for transdisciplinarity in management education and research. Kybernetes, 30 (9/10), pp.1209-1222.

Sellami, M., Gaaloul, W. \& Tata, S. (2011). An implicit approach for building communities of web service registries. In: Proceedings $13^{\text {th }}$ International Conference on Information Integration and Web-based Applications and Services (ii- WAS).

Speyerer, J.K. \& Zeller, A.J. (2004). Managing supply networks: symptom recognition and diagnostic analysis with web services. In: Proceedings $37^{\text {th }}$ Hawaii International Conference on System Sciences (HICSS).

Swedberg, C. (2008). EPCglobal transportation and logistics pilot takes visibility to a global level. RFID Journal, http://www.rfidjournal.com/articles/pdf?4199 (accessed on 24.04.2015).

Tanja, P.T. \& Ruijgrok, C.J. (1990). Logistical information systems and their importance for integral logistical control. Transports, (339), pp. 8-16. 
Tribowski, C., Goebel, C., \& Günther, O. (2009). EPCIS-based supply chain event management - a quantitative comparison of candidate system architectures. In: Proceedings International Conference on Complex, Intelligent Software Intensive Systems (CISIS).

Tröger, R. (2014). Supply Chain Event Management - Bedarf, Nutzen und Systemarchitektur aus Perspektive fokaler Unternehmen der Modeindustrie. Doctoral Thesis, http://nbn-resolving.de/urn:nbn:de:bsz:15-qucosa-155014.

Wei, H.-L. \& Wang, E.T.G. (2010). The strategic value of supply chain visibility: increasing the ability to reconfigure. European Journal of Information Systems 19 (2), pp. 238-249.

Wessel, R. (2007). ThyssenKrupp to use EPC UHF tags to track steel. In: RFID Journal; http://www.rfidjournal.com/articles/view?3306 (accessed on 27.12.2013).

Wyllie, D. (2013). Moderne ERP-Lösungen aus der deutschen Cloud. In: Computerwoche, October 2013; http://www.computerwoche.de/a/moderne-erp-loesungen-aus-der-deutschencloud,2541640 (accessed on 30.11.2013).

Yin, R. (2009). Case study research: design and methods, $4^{\text {th }}$ edition, Thousand Oaks.

Zimmermann, R., Winkler, S. \& Bodendorf, F. (2006). Agent-based supply chain event management - concept and assessment. In: Proceedings $39^{\text {th }}$ Hawaii International Conference on System Sciences (HICSS). 


\section{Appendix: Core questions of semi-structured interviews}

\begin{tabular}{|c|c|c|}
\hline \multicolumn{3}{|c|}{ Part 1: general questions } \\
\hline No. & Question & Purpose \\
\hline 1 & $\begin{array}{l}\text { What is your area of responsibility with your organi- } \\
\text { zation? }\end{array}$ & $\begin{array}{l}\text { Assessing representativeness of in- } \\
\text { formant(s) }\end{array}$ \\
\hline 2 & $\begin{array}{l}\text { For how have you been working with your organiza- } \\
\text { tion and how long have you been in your current job? }\end{array}$ & $\begin{array}{l}\text { Determining expertise/experience of } \\
\text { informant(s) }\end{array}$ \\
\hline 3 & Please describe/characterize your organization. & $\begin{array}{l}\text { Gathering details/information regard- } \\
\text { ing company }\end{array}$ \\
\hline 4 & $\begin{array}{l}\text { How would you describe/characterize the industry } \\
\text { your organization belongs to? }\end{array}$ & $\begin{array}{l}\text { Comprehending business context and } \\
\text { sector-specific characteristics }\end{array}$ \\
\hline 5 & $\begin{array}{l}\text { Please outline the major business processes of your } \\
\text { organization. }\end{array}$ & Gaining business process overview \\
\hline 6 & $\begin{array}{l}\text { Please explain your organization's logistics/supply } \\
\text { chain structures. }\end{array}$ & $\begin{array}{l}\text { Gaining insights as to flow of goods, } \\
\text { general conditions, business partners, } \\
\text { supply chain dependencies }\end{array}$ \\
\hline
\end{tabular}

\begin{tabular}{|l|l|l|}
\hline \multicolumn{2}{|l|}{ Part 2: Visibility-related questions } \\
\hline No. & Question & Purpose \\
\hline 1 & What do you understand by ‘visibility’? & $\begin{array}{l}\text { Assessing the informant's understand- } \\
\text { ing of the term }\end{array}$ \\
\hline 2 & $\begin{array}{l}\text { With regard to the major business processes we dis- } \\
\text { cussed earlier - which visibility data does your organ- } \\
\text { ization require when and why? }\end{array}$ & $\begin{array}{l}\text { Deriving organization's critical track- } \\
\text { ing events }\end{array}$ \\
\hline 3 & $\begin{array}{l}\text { Are you aware of visibility requirements of your busi- } \\
\text { ness partners? If so, which visibility data do they re- } \\
\text { quire when and why? }\end{array}$ & $\begin{array}{l}\text { Determining whether organization has } \\
\text { knowledge about visibility goals of } \\
\text { business partners; deriving externally } \\
\text { required CTEs }\end{array}$ \\
\hline 4 & $\begin{array}{l}\text { How do you/your business partners identify their } \\
\text { business objects (products, logistics units, etc.)? }\end{array}$ & $\begin{array}{l}\text { Determining granularity of identifica- } \\
\text { tion and level of standardization }\end{array}$ \\
\hline 5 & $\begin{array}{l}\text { Which data carriers (if any) do you/your business } \\
\text { partners make use of? }\end{array}$ & $\begin{array}{l}\text { Getting overview of data carriers; de- } \\
\text { termining level of standardization }\end{array}$ \\
\hline
\end{tabular}




\begin{tabular}{|c|c|c|}
\hline \multicolumn{3}{|c|}{ Part 3: Questions as to EPCIS/visibility service } \\
\hline No. & Question & Purpose \\
\hline 1 & What do you understand by EPCIS? & $\begin{array}{l}\text { Assessing informant's level of under- } \\
\text { standing }\end{array}$ \\
\hline 2 & $\begin{array}{l}\text { Your organization is known to be an adopter of } \\
\text { EPCIS. Is that correct? }\end{array}$ & $\begin{array}{l}\text { Confirmation of knowledge obtained in } \\
\text { secondary literature }\end{array}$ \\
\hline 3 & How long have you been using EPCIS so far? & $\begin{array}{l}\text { Determining experience in applying } \\
\text { EPCIS and whether organization is an } \\
\text { early/middle/late adopter }\end{array}$ \\
\hline 4 & $\begin{array}{l}\text { In which use cases/projects have you been using } \\
\text { EPCIS? }\end{array}$ & $\begin{array}{l}\text { Getting overview on areas of applica- } \\
\text { tion }\end{array}$ \\
\hline 5 & $\begin{array}{l}\text { In addition to the last question - which EPCIS event } \\
\text { types are used and which data do they accommodate? }\end{array}$ & $\begin{array}{l}\text { Gaining insight into message } \\
\text { types/contents; determining whether } \\
\text { EPCIS events correspond with organi- } \\
\text { zation's visibility need discussed ear- } \\
\text { lier; determining whether organization } \\
\text { makes use of standard vocabulary ele- } \\
\text { ments }\end{array}$ \\
\hline 6 & $\begin{array}{l}\text { How is EPCIS integrated in your organization's sys- } \\
\text { tem landscape? }\end{array}$ & $\begin{array}{l}\text { Gaining insight as to technical realiza- } \\
\text { tion (e.g. local vs. cloud-based imple- } \\
\text { mentation, applications capturing/que- } \\
\text { rying EPCIS event data, etc.) }\end{array}$ \\
\hline 7 & $\begin{array}{l}\text { Explain which business applications consume EPCIS } \\
\text { event data and how they are provided with the data. }\end{array}$ & $\begin{array}{l}\text { Deriving level of reutilization of ser- } \\
\text { vice; determining internal/ external us- } \\
\text { age and query methods }\end{array}$ \\
\hline 8 & $\begin{array}{l}\text { Why did your organization decide to apply EPCIS in } \\
\text { the first place? }\end{array}$ & $\begin{array}{l}\text { Understanding motivation of imple- } \\
\text { mentation decision }\end{array}$ \\
\hline 9 & $\begin{array}{l}\text { Both from a business and technical point of view - } \\
\text { what is the major value added of EPCIS? }\end{array}$ & $\begin{array}{l}\text { Comprehending/proving business-re- } \\
\text { lated and technical-driven benefits of } \\
\text { EPCIS }\end{array}$ \\
\hline 10 & $\begin{array}{l}\text { Does your organization intend to use EPCIS for fur- } \\
\text { ther projects/use cases within the next twelve } \\
\text { months? }\end{array}$ & $\begin{array}{l}\text { Gathering information as to future } \\
\text { plans/further utilization }\end{array}$ \\
\hline
\end{tabular}

